\title{
Laboreal
}

Volume $7 \mathrm{~N}^{\circ} 1 \mid 2011$

Psicodinâmica e psicopatologia do trabalho

\author{
“ Trabalhar " não é " derrogar " [] \\ "Trabajar" no es "derogar" \\ "Travailler" n'est pas " déroger" \\ "Working" is not " derogating"
}

\section{Christophe Dejours}

Tradutor. Andreia Ferreira e João Viana Jorge

\section{CpenEdition}

\section{Journals}

\section{Edição electrónica}

URL: http://journals.openedition.org/laboreal/8354

DOI: 10.4000/laboreal.8354

ISSN: 1646-5237

\section{Editora}

Universidade do Porto

\section{Refêrencia eletrónica}

Christophe Dejours, " "Trabalhar " não é " derrogar " [ », Laboreal [Online], Volume 7 Nº1 | 2011, posto online no dia 01 julho 2011, consultado o 10 outubro 2019. URL : http://journals.openedition.org/ laboreal/8354; DOl : 10.4000/laboreal.8354

Este documento foi criado de forma automática no dia 10 outubro 2019.

\section{cc) (7) (5)}

Laboreal está licenciado com uma Licença Creative Commons - Atribuição-NãoComercial 4.0 Internacional. 


\title{
“Trabalhar " não é " derrogar " [1]
}

\author{
"Trabajar" no es "derogar" \\ "Travailler" n'est pas " déroger" \\ "Working" is not " derogating"
}

\section{Christophe Dejours}

Tradução : Andreia Ferreira e João Viana Jorge

\section{REFERÊNCIA}

Artigo original : Dejours, Ch. (1998) “ Travailler " n'est pas “ déroger ”. Travailler, 1, 5-12.

1 Salvo se fizermos remontar a origem da psicopatologia do trabalho a Tissot - De la santé des gens de lettres, 1768 - é geralmente consensual considerar que a investigação sobre as relações entre trabalho e saúde mental têm sensivelmente 50 anos de idade. É pouco se compararmos com a psiquiatria ou com a patologia profissional (Ramazzini, De morbis artificum diatribs, 1700). É muito se compararmos com a engenharia genética ou com a neuroquímica (Guillemin, Prémio Nobel da Biologia e Medicina pela descoberta das endorfinas, 1977). Cada um desses campos disciplinares alimenta numerosas revistas pelo mundo fora. Porque não acontece o mesmo com a psicopatologia do trabalho ? 0 campo da saúde mental no trabalho é todavia vasto, as suas incidências na saúde pública são evidentes, a sua importância teórica mede-se pelo lugar que o trabalho ocupa na vida normal de cada um, e na condição humana em geral... !

2 É que o nascimento e desenvolvimento das revistas não dependem da importância económica, social ou política de um campo, mas da actividade científica que se desenrola no seu seio e dos desafios, ou até paixões, que aquela última suscita. É forçoso reconhecer que, no campo da saúde mental no trabalho, as actividades científicas eram reduzidas e que não suscitavam grande paixão. lugar em Paris, no Conservatoire National des Arts et Métiers, em Janeiro de 1997, 
proporcionou uma visão diferente desse panorama: a visão de uma numerosa participação de profissionais, entre os quais uma maioria de médicos do trabalho, mas também grande número de ergónomos, de assistentes sociais, de psicólogos, de psiquiatras, de psicanalistas; a de uma presença intelectual assegurada por investigadores e universitários operando nas disciplinas já citadas, às quais se devem acrescentar a sociologia, a antropologia, a economia e a epidemiologia ; enfim, a de uma contribuição internacional com as comunicações de colegas provenientes de numerosos países da Europa, África e América.

4 Foi para poder estruturar o campo da psicodinâmica e da psicopatologia do trabalho e para poder acolher e difundir os relatos de experiências práticas assim como de investigações científicas, para constituir, enfim, um espaço de discussão que a revista Travailler foi fundada pelos membros do comité científico do colóquio de 1997. Trabalhar: porquê este título ? Primeiro que tudo para ganhar algum distanciamento face aos debates sobre o trabalho e sua definição. Trabalho, actividade, emprego, profissão, qualificação..., todos estes termos têm conotações disciplinares e conceptuais específicas que suscitam controvérsias sobre o sentido apropriado a dar ao termo trabalho. Controvérsias de um grande interesse que mostram contudo que nenhuma definição da noção de trabalho conseguiria chegar, actualmente, a um consenso. Para certos autores cujas opiniões beneficiaram nestes últimos anos de uma admiração entusiástica por parte do público, o trabalho está mesmo em vias de extinção! Para outros, o trabalho é uma construção social recente que data do início ou de meados do século XIX. Para outros ainda o trabalho não teria aparecido senão com o protestantismo e a Reforma... deixemos então esses debates e debrucemo-nos sobre uma realidade indiscutível : trabalhar. Quer se trate de uma actividade assalariada ou graciosa, doméstica ou profissional, de operador ou de quadro, no público ou no privado, na indústria ou nos serviços, na agricultura ou no comércio...trabalhar é mobilizar o seu corpo, a sua inteligência, a sua pessoa para uma produção que detenha valor de uso.

o deslocamento conceptual da noção de "trabalho" para a de "trabalhar", é importante. Devemo-lo a Simone Bateman-Novaes que a tinha sugerido no fim do simpósio "satélite" do Colóquio Internacional de Janeiro de 1997. Trabalhar será primeiro entendido como um verbo incoactivo, mas poderá eventualmente beneficiar de uma substantivação, como se diz de: o deitar, o comer, o beber ou o agir. 0 "Trabalhar" designa uma realidade liberta das polémicas, por vezes bizantinas, sobre a realidade do trabalho. Nesta revista, o termo trabalho remeterá portanto, antes de qualquer outra coisa, para o "trabalhar" cuja experiência corrente é desde sempre consubstancial com o humano.

\section{Os poderes do trabalho}

6 Se trabalhar se reveste de uma tal importância antropológica é, seguramente, porque é primeiro que tudo uma actividade de produção que transforma o mundo e pode assim torná-lo mais habitável. 0 trabalho contém essa promessa, mesmo que esta última, por demais o sabemos, se possa transformar em ameaça. Não há dúvidas de que o futuro da Terra, como habitat do homem, depende da maneira como este trabalha. Mas o trabalho é também uma actividade de produção onde se concretizam e se objectivam a inteligência e o engenho humanos. Sem produção, sem fabrico, noutros termos, sem 
trabalho, a inteligência e a criatividade humanas não seriam mais do que hipóteses. Estes dois poderes do trabalho - ordenamento do mundo e objectivação da inteligência - são tradicionalmente reconhecidos pelas ciências humanas. Quanto à revista Travailler esforçar-se-á por dar um lugar de eleição a um outro poder do trabalho que a tradição não considera senão com circunspecção : o poder de fazer advir o sujeito.

7 Trabalhar, não é somente produzir ou fabricar, não é apenas transformar o Mundo, é também transformar-se a si próprio, produzir-se a si mesmo. Noutros termos, é através do trabalho que o sujeito se forma ou se transforma revelando-se a si próprio de tal forma que depois do trabalho ele já não é completamente o mesmo do que antes de o ter empreendido. Assim, trabalhar participa num processo de subjectivização ao qual o clínico, preocupado com a saúde mental, dedica mais atenção ainda do que ao processo de objectivação. Porquê? Porque decorre da própria substância da subjectividade produzida pelo trabalho. A montante do trabalho existe, com efeito, o sofrimento. E é precisamente esse sofrimento que o "trabalhar" tem poder para transformar em sentimento de prazer.

Como é que o trabalhar pode transformar o sofrimento ? Não engendra o trabalho bem maior sofrimento do que o que é capaz de esconjurar? A própria psicopatologia do trabalho situar-se-ia nos antípodas da medicina do trabalho, a primeira oferecendo-se como ciência da felicidade enquanto a segunda seria a ciência do infortúnio. Numa versão tão caricatural dessa oposição, ninguém conseguiria encontrar-se. Existe, todavia, efectivamente, uma inflexão diferente entre as duas disciplinas clínicas: a medicina do trabalho como toda a medicina, preocupa-se em descrever as lesões ou as doenças para poder de seguida tratá-las ou preveni-las. A psicodinâmica do trabalho preocupa-se também com a patologia mas interessa-se, por acréscimo, pela normalidade e, além disso, pela saúde (mesmo que esta última seja concebida como um ideal inatingível). Não se trata somente de proteger os homens e as mulheres da devastação originada pelo trabalho, mas de fazer em vez disso com que "trabalhar" seja restituído ao seu poder constitutivo da saúde.

\section{O trabalho e o seu sujeito}

Retenhamos de algumas destas considerações que o trabalho é ambíguo do ponto de vista da vida : pode provocar o pior - a doença e a morte - mas pode também gerar o melhor - saúde e acréscimo de vida. Esta ambivalência, o trabalho obtêm-na da sua relação com a subjectividade e com o sujeito. Já vimos anteriormente os três poderes do trabalhar: transformação do mundo, objectivação da inteligência, produção da subjectividade. Mas o "trabalhar", de onde retira ele o seu poder incoactivo ? Ou, para o dizer de outra forma, o que é que põe o "trabalhar" em movimento ? Para esta questão não há senão uma resposta possível : o sujeito. É o próprio sujeito que inicia o trabalhar que ele mesmo usa para se aperfeiçoar e se engrandecer a si próprio.

Antes de qualquer trabalho há portanto um sujeito, ainda que em estado inacabado, que o mesmo é dizer, à espera de uma evolução, porventura de um advento. Se, partindo desse duplo processo de objectivação e subjectivização que caracteriza o trabalho, tomarmos emprestado um caminho que retroceda, encontramos, a montante do trabalhar, um sujeito. Mas então é inevitável colocar a questão da origem desse sujeito que força a trabalhar. A resposta deve ser procurada, mais uma vez, do lado do sofrimento a que se fez anteriormente breve menção, na condição de não reter senão as 
conotações convencionais da noção em virtude das quais o sofrimento estaria inteiramente do lado da paixão, do ressentido, do suportado e do infortúnio. Isto faznos avançar no sentido de um paradoxo onde se situa verdadeiramente a dificuldade teórica principal. Não é necessária grande ilustração para tomar consciência de que o trabalho possa gerar o pior e o melhor. Que sofrer, em contrapartida, possa ter incidências favoráveis é mais dificilmente aceitável. Todavia, contrariamente ao que sugere o senso comum, o sofrimento não é simplesmente o resultado final de um encadeamento infeliz de que não restaria senão deplorar as aborrecidas e lamentáveis consequências. $O$ sofrimento é também, para o clínico do trabalho, um ponto de partida, uma origem : a origem de todo o movimento em direcção ao mundo, de toda a experiência do mundo. Sofrer é ontologicamente a ligação primordial do sujeito ao mundo. E, ao sujeito nada mais resta senão esse sofrimento experienciado, reconhecido, apropriado. Só então pode começar lentamente a mutação no seu contrário. Se o prazer é um dos destinos possíveis do sofrimento, é preciso reconhecer à partida que o sofrimento o antecede. Não há de facto nenhum sujeito que não seja o resultado do sofrimento, apenas a partir do sofrimento, na estrita medida todavia em que esse sofrimento seja efectivamente experienciado no meu corpo e pelo meu corpo. Porque não há afectividade sem carne. E o sofrimento é afectivo na medida em que me é revelado pelo meu corpo. Assim, corpo e sofrimento engendram o sujeito.

11 Pouco importa a origem do sofrimento, seja ele causado por um sentimento endógeno de incompletude ou provenha de um poder deletério vindo do exterior. É suficiente que esse sofrimento seja carnalmente experienciado para que apele de algum modo a ser ultrapassado. O sofrimento, mesmo sendo doloroso é ao mesmo tempo protensão dirigido para o mundo, em busca de novas ocasiões para pôr o sujeito à prova : à prova do mundo e à prova de si mesmo, para se ultrapassar, para se realizar. Como ? Pelo trabalho precisamente! O sofrimento como protensão dirigido para o mundo é fundamentalmente protensão do sujeito para "trabalhar": trabalhar esse sofrimento para o transformar, relevar o desafio para se engrandecer e se realizar como sujeito. Trabalhar não é derrogar as obrigações que se têm face à sua própria dignidade. É mesmo completamente o contrário. A posteriori, quando da contemplação dos resultados do trabalho realizado, anuncia-se a ultrapassagem do sofrimento e a sua transformação em sentimento de satisfação, de plenitude e até de euforia. $O$ prazer no trabalho está consubstancialmente ligado ao sucesso do processo de subjectivização, de reforço da identidade, ou ainda à auto-realização, que o trabalhar proporcionou.

\section{Trabalho e dominação}

12 Então se a teoria em psicodinâmica do trabalho está em posição de argumentar o potencial mutante do "trabalhar" sobre o sofrimento, para o fazer engendrar um reforço de identidade e de subjectividade, porque é que a clínica produzida pela psicopatologia e pela psicodinâmica se dá a conhecer, antes de tudo, pela descrição dos destinos funestos do sofrimento, pela dos mecanismos de defesa, da alienação e da patologia mental?

13 Porque, se "trabalhar" consiste primordialmente - isto é, com uma anterioridade ontológica e genealógica - numa relação do sujeito consigo mesmo na procura de situações para se testar a si próprio e se realizar, o trabalho não é acessível, concretamente, senão numa relação social em que se exerce a dominação. A redução do 
emprego e a sua flexibilização são desse ponto de vista suficientemente espectaculares para que seja inútil comentá-las. Mas, mais trivialmente, sabe-se que o potencial mutante do trabalho sobre o sofrimento, sobre o aumento da subjectividade, sobre o prazer e sobre a saúde, pode ser neutralizado. Até mesmo convertido no seu contrário e não engendrar senão mais sofrimento sem qualquer possibilidade de fazer a sua análise [2]. Como, por exemplo, no trabalho repetitivo sob constrangimentos de tempo. Perfilase assim um novo desafio : o da subversão da dominação, pelo trabalho. Desafio que não é aberrante nem delirante como o sugere a emancipação das mulheres em relação à dominação dos homens precisamente através do trabalho. Mas nós sabemos que a solução desta negociação, que constitui a organização do trabalho real, é incerta e que pode revestir formas muito contrastadas. De facto é possível vergar e inclinar-se perante a dominação, cuja organização do trabalho constitui um desafio, ou então usar esperteza e resistir. Que a nossa liberdade, a nossa responsabilidade e a nossa vontade estejam comprometidas no destino da relação com o trabalho é incontestável. Mas para poder assumir o que isto implica no registo da acção, devemos desenvolver os instrumentos conceptuais e uma aparelhagem teórica que permita analisar o que faz com que uma organização do trabalho seja favorável ao advento do sujeito ou pelo contrário aquilo que a torna fundamentalmente deletéria e des-subjectivante ou ainda alienante. Já evocamos a não neutralidade do trabalho face à auto-realização: ou contribui para o engrandecimento do sujeito ou contribui para a sua destruição; ou é um potente meio para construir e defender a saúde; ou se transforme numa arma temível em proveito da desintegração da subjectividade e da sua morte. Esta é, no fim de contas, a dimensão trágica do trabalho que nesta revista deve ter um lugar de elaboração, análise e discussão.

\section{Trabalho e acção}

14 Do que precede, ter-se-á compreendido que a psicodinâmica e a psicopatologia do trabalho são fundamentalmente atravessadas pelas questões relativas à acção: acção cujo objectivo primordial é o planeamento das situações de trabalho, de maneira que sejam aí agrupadas as condições propícias ao acréscimo da subjectividade e da vida. Não se trata de todo de uma quimera irrisória. Numerosas são as situações de trabalho graças às quais os homens e as mulheres se aguentam melhor que quando são privados do trabalho. É que nestes casos, os conflitos de racionalidade, indubitáveis e inevitáveis foram ultrapassados pelo compromisso de qualidade entre a racionalidade do sofrimento e do seu advir e as racionalidades moral prática e estratégica. Convém ainda precisar que estes compromissos não são o resultado de conjunturas particularmente favoráveis ou aleatórias, mas, de facto, de intenções, de vontades e de decisões deliberadas. Impossível atingir compromissos bem sucedidos sem libertar espaços de elaboração e de deliberação ; sem consagrar tempo para reflectir ; tempo para pensar as condições e a organização do trabalho. Os bons compromissos existem, mas é preciso inventá-los, defendê-los, fazê-los evoluir. o desafio da aç̧ão, é aqui o espaço que queremos defender para a subjectividade e para a vida no mundo do trabalho e, para além disso, nas instituições e na organização da cidade. 


\section{Acção, praxis e teoria}

Por mais que esta nova revista reflicta as preocupações formuladas por um grande número dos seus potenciais leitores, relativamente à acção no campo da saúde no trabalho, ela não tem por vocação dar ou propor modos de utilização. A acção não consiste na aplicação de procedimentos ou na execução de instruções. Ela passa por decisões sapientes. E a sapiência, aqui entendida como sapiência prática, supõe não somente agir com autenticidade mas agir convenientemente. Uma acção é tanto mais conveniente quanto mais rigorosamente pensada ela é. Para isto é preciso poder apoiar-se em conhecimentos, teorias e conceitos, isto é na sedimentação do trabalho dos outros, de todos os outros, de todos os membros da comunidade a que pertence. Esta é a vocação da revista : centralizar e difundir conhecimentos, colocar em debate as problemáticas.

Agir racionalmente supõe, a posteriori e não apenas na deliberação antecedente, submeter a acção à prova dos conceitos. Característico de uma acção racional é ser orientada para objectivos possíveis. Uma acção é irracional no seu objectivo se designa os inatingíveis porque eles não resultam da vontade nem da decisão, porque o estado das coisas não pode ser outro senão aquele que é, porque o objectivo visado está fora do alcance de toda a vontade humana. Por exemplo bater-se por um compromisso de qualidade entre trabalho e saúde é um objectivo acessível e racional. Em contrapartida propor-se, como fim a atingir, a supressão do sofrimento humano, é formular um objectivo impossível de atingir e envolver-se numa acção irracional. Determinar se um objectivo é quimérico ou realista não é evidente. É por isso que agir não consiste apenas em tomar decisões. Agir supõe despender tempo para reflectir e para estudar. Os grupos de trabalho, os seminários de que se dotaram sucessivamente os psiquiatras, os psicanalistas, e mais recentemente colectivos de médicos do trabalho e médicos generalistas, constituem uma das formas mais poderosas de enriquecimento da aç̧ão no campo da saúde no trabalho.

Travailler deveria ser um instrumento ao serviço da deliberação.

Travailler quer-se uma revista amplamente aberta aos debates, mas fortemente argumentada do ponto de vista teórico. É por isso que ela se dotou de uma comissão de leitura em quem recairá a responsabilidade não só de aceitar ou recusar os artigos submetidos para publicação, mas também a de fixar as orientações editoriais. Não para fabricar um "produto" que constituiria uma montra de uma dita excelência, mas para oferecer à comunidade um meio suplementar de trabalhar e de se engrandecer. $O$ leque de artigos esperados é portanto alargado porque poderão ser publicadas na revista contribuições emanadas de todas os ramos das ciências humanas assim como das ciências da engenharia ou das ciências biomédicas, na medida em que, tratando do trabalho ou da acção, elas não atribuam ao sofrimento e ao sujeito apenas um estatuto de acessório decorativo, antes lhes atribuam um espaço significativo sustentado por referências explicitamente situadas.

19 Um convite, de todo o modo, a ler, a escrever, a trabalhar e a fazer trabalhar, um convite endereçado a cada uma daquelas e a cada um daqueles que se reconhecem no projecto de desenvolver uma clínica do trabalho e de acção no centro da qual terá sido deliberadamente decidido colocar a questão do sujeito.

Julho de 1998 


\section{NOTAS}

1. Derrogar: perder os privilégios da nobreza por exercício de uma profissão incompatível com ela, ver (Diccionnaire Robert de la langue française) N.T.-. Em português o significado de derrogar não é (pelo menos actualmente) este; todavia o autor usa, no texto, o termo com o sentido que ele tem em português: o de anular ou revogar.

2. NT - Em Francês o autor utilizou a palavra "perlaboration" que é um neologismo inventado para traduzir o termo: Durcharbeitung (Travail "à travers").

\section{AUTORES}

\section{CHRISTOPHE DEJOURS}

Conservatoire National des Arts et Métiers, 41, Rue Gay-Lussac, 75005 Paris

Christophe-dejours@cnam.fr 